\title{
AS DELEGACIAS ESPECIAIS DE PROTEÇÃO À MULHER NO BRASIL E A «JUDICIARIZAÇÃO» DOS CONFLITOS CONJUGAIS*
}

\author{
Theophilos Rifiotis**
}

Sejam quais forem as outras características que a antropologia e a jurisprudência possam ter em comum - como, por exemplo, uma linguagem erudita meio incompreensível e uma certa aura de fantasia - ambas se entregam à tarefa artesanal de descobrir princípios gerais em fatos paroquiais. Repetindo, uma vez mais, o provérbio africano: "a sabedoria vem de um monte de formigas".

C. Geertz

Resumo: Os movimentos sociais que lutam contra a impunidade nos casos de "violência conjugal" são, ao mesmo tempo, movimentos locais e globais, cuja dimensão transversal representa um desafio maior e coloca a necessidade de pesquisas comparativas entre "soluções locais". A delegacia da mulher é dispositivo de polícia judiciária criado no Brasil como parte da luta contra a impunidade e ampliação do acesso à justiça. Uma re-leitura da pesquisa etnográfica realizada na Delegacia da Mulher de João Pessoa (Paraíba, Brasil) é apresentada a partir do estudo das políticas e experiências canadenses que tiveram lugar no Quebec, especialmente junto ao Serviço de Polícia da Comunidade Urbana de Montreal (SPCUM). O presente texto é um ensaio sobre a "especificidade" da experiência brasileira e tem como objetivo contribuir para a discussão deste tipo de processo de "judiciarização".

Palavras-chave: violência conjugal, delegacia da mulher, justiça, polícia, judiciarização

* Trabalho publicado no Anuário 2003. Direito e Globalização. Atas do Seminário do GEDIM, Universidade Cândido Mendes. Rio de Janeiro, Editora Lumen Juris/UNESCO/ MOST, 2003, p. 381-409.

** Departamento de Antropologia da Universidade Federal de Santa Catarina.

Artigo recebido em 08 dez. 2003; aprovado em 18 jun. 2004. 


\section{Apresentação}

O presente trabalho é resultado de uma pesquisa etnográfica realizada na Delegacia da Mulher do município de João Pessoa, no Estado da Paraíba, entre janeiro e abril de 1999. ${ }^{1}$ Ele tornou-se possível pelas relações estabelecidas com as delegadas e agentes policiais daquela delegacia durante os cursos de capacitação organizados pela Universidade Federal da Paraíba (UFPB), em convênio com Secretaria de Segurança Pública daquele Estado, dos quais participamos como professor. Durante os cursos foi apresentada uma abordagem crítica das noções de "violência" e "violência conjugal", fundamentada na análise teórica da p a "violência" é uma noção homogeneizadora e, como tal, confunde-se com um "problema social" e "moral", não sendo portanto uma categoria científica (Rifiotis, 1997, 1999a, 2001). Assim, tratando-se de abordagem teórica complexa e polêmica, causou-nos surpresa o fato de as policiais alunas a identificarem com os seus atendimentos quotidianos na Delegacia da Mulher, como ocorreu com a análise relacional dos conflitos interpessoais envolvendo laços afetivos e conjugais (Gregori, 1987; Grossi, 1995), e os limites da leitura dicotômica e polar contida nas figuras de "vítima" e "agressor".

A empatia que se estabeleceu naquele momento criou um clima propício à pesquisa de campo na Delegacia da Mulher de João Pessoa, o qual foi favorecido pela ressignificação que as delegadas, e, sobretudo as policiais, deram às suas insatisfações e frustrações no atendimento das mulheres que procuram os seus serviços a partir da leitura teórica proposta nos cursos. A ressignificação a que nos referimos aqui é da maior importância para a valorização da instituição e das policiais que trabalham na Delegacia da Mulher. Afinal, num quadro de críticas e insatisfação com aquele trabalho policial, a pesquisa representava uma possibilidade de mostrar um "fazer polícia" diferente, o que ficou bastante evidente durante o trabalho de campo. ${ }^{2}$

Contando com o necessário apoio das delegadas e a autorização das queixosas, foi possível realizar o trabalho de observação direta e continuada das práticas policiais na Delegacia da Mulher, ${ }^{3}$ o que nos 
permitiu presenciar os atendimentos, ouvir os relatos sofridos daquelas mulheres, observar a reação das delegadas, das escrivãs, acompanhar o preenchimento dos chamados boletins de ocorrência, a tomada de depoimentos, as discussões informais sobre os casos, os momentos de confronto entre as queixosas e os intimados. A observação também possibilitou que nos déssemos conta concretamente da variedade de tipos de casos atendidos e observar o trabalho das assistentes sociais e da psicóloga. ${ }^{4}$ Pudemos constatar a precariedade das instalações e de formação; as longas discussões quotidianas sobre os locais para entrega das intimações, dada a recorrente falta de endereço formal do público atendido; os momentos de tensão, de controvérsia, que se mostraram ao longo do trabalho, ponto central dos atendimentos; a construção dos pactos informais entre as partes e as orientações dadas pelas delegadas. Enfim, uma riqueza de material etnográfico que serviu de base para este texto e que não se esgota aqui.

Os dados coletados na pesquisa foram analisados durante $o$ período de pesquisador visitante no Centre International de Criminologie Comparée (CICC), da Universidade de Montreal, quando realizamos, além de estudos teóricos sobre os serviços de polícia, um trabalho de pesquisa no Service de Police de la Communauté Urbaine de Montreal (SPCUM) e com a Sûreté du Québec (SQ). ${ }^{5}$ Inicialmente, com uma aproximação mais teórica com o professor Jean-Paul Brodeur, do CICC, e num segundo momento com entrevistas e observação direta num distrito policial (Poste de Quartier, abreviado PQ) adotando o modelo de polícia comunitária e sobre as práticas no âmbito da "violência conjugal". Desde a primeira conferência que fizemos na Universidade de Montreal sobre a Delegacia da Mulher, chamou-nos a atenção o fato de que à curiosidade pelo "exótico" da experiência brasileira somava-se uma identificação com os problemas encontrados pelos pesquisadores e pelos próprios policiais no seu quotidiano no Canadá. Essa impressão foi reforçada durante as entrevistas realizadas com policiais da SPCUM e SQ, mostrando que, apesar das evidentes diferenças históricas e culturais entre o Brasil e o Canadá, havia nessa matéria algo em comum que era preciso identificar. 
Da confluência do trabalho de campo realizado no Brasil com o estudo das experiências canadenses, especialmente da SPCUM e SQ, surgiu o interesse pelo estudo comparativo das políticas e práticas policiais nesses países no campo da "violência conjugal". A proposta de refletir sobre as aproximações e diferenças entre tais estratégias locais de ação procura ultrapassar a simples busca de equivalências formais entre elas e não objetiva definir soluções aplicáveis fora dos seus contextos de origem.

A rigor, a perspectiva comparativa, com todas as suas limitações, impôs-se também por razões históricas relativas aos movimentos feministas. Como sabemos, esses movimentos estão na base social das reivindicações que deram visibilidade à "violência conjugal" e a transformaram em fenômeno público, ou seja, trata-se de fenômeno que deve ser considerado como resultante de processos locais e globais. Afinal, assim como a delegacia da mulher no Brasil, as políticas de "violência conjugal" no Canadá são resultantes de um amálgama de tendências globalizantes e adequações locais a partir das quais são definidas políticas locais de atuação.

Em muitos países, é o recurso aos serviços de polícia e de modo geral ao sistema judiciário que caracteriza as políticas públicas contra a "violência conjugal". Na realidade, trata-se da criação de mecanismos jurídicos para ampliar o acesso ao sistema de justiça a causas antes consideradas da ordem privada, possibilitando reduzir a impunidade. Para os objetivos do nosso trabalho é importante destacar a prevalência das soluções locais articuladas em torno da criação de mecanismos de curto prazo que privilegiam a leitura jurídica dos conflitos interpessoais, a qual se inscreve num amplo processo que podemos chamar de "judiciarização". ${ }^{6}$

Seguindo Weber, afirmamos que a forma de legitimidade mais importante na sociedade moderna consiste em crer na legalidade. Afinal,

L'ordre que l'on respecte uniquement pour des motifs rationnels en finalité est en général beaucoup plus instable que si l'orientation se fait purement et simplement en vertu de la coutume, en raison du 
caractère routinier d'un comportement; c'est même là, de toutes les espèces d'attitudes intimes, la plus courante. Néanmoins cet ordre est encore incomparablement moins stable que celui qui s'affirme grâce au prestige de l'exemplarité et de l'obligation, je veux dire de la légitimité. (Weber, 1995a., p. 65)

Por essa razão, ainda que a forma de legitimidade mais corrente seja a crença na legalidade, como lembra o próprio Weber (1995b, 73), há um resto no domínio dos conflitos interpessoais que é a dimensão privada, que ainda é significativa e mostra uma situação complexa e contraditória entre os campos do domínio público e privado. Jacques Commaille bem expressou tal situação nos seguintes termos:

Si l'on résumait d'un mot cette contradiction du privé en ayant à l'esprit cette question des violences intra-familiales, nous pourrions dire que l'espace privé aurait tendance à se protéger de l'intrusion du public tout en ne pouvant plus échapper à la nécessité croissante de le solliciter. (Commaille, 1997, p. 11)

É preciso esclarecer desde logo que não se trata de questionar a importância dos mecanismos judiciários nos conflitos intrafamiliares, mas apontar que esse tipo de leitura não pode ser exclusivo, e que a criminalização de tais conflitos é problemática. Ao longo deste trabalho, a "judiciarização" é apresentada como conjunto de práticas e valores, pressupostos em instituições como a Delegacia da Mulher, e que consiste fundamentalmente em interpretar a "violência conjugal" a partir de um ponto de uma leitura criminalizante e estigmatizada contida na polaridade "vítima-agressor", ou na figura jurídica do "réu". A leitura criminalizadora apresenta uma série de obstáculos para a compreensão e intervenção nos conflitos interpessoais. Como procuramos mostrar neste trabalho, ela é teoricamente questionável, não corresponde às expectativas das pessoas atendidas nas delegacias da mulher e tampouco ao serviço efetivamente realizado pelas policiais naquela instituição.

Assim, cônscios de que a comparação é a um só tempo recurso necessário e impossível de ser realizado plenamente, optou-se por adotar como postura metodológica a "tradução cultural", como sugere 
C. Geertz (1998) no seu célebre artigo "O saber local: fatos e leis em uma perspectiva comparativa". Trata-se de perspectiva analítica que procura criar uma "tradução" no sentido etimológico de "trazer o sentido", ou seja, iluminar o sentido de uma manifestação cultural por intermédio de outra, permitindo que elas se transformem uma em comentário da outra, iluminando o que a outra obscurece e vice-versa. Em outros termos, os comparáveis e os incomparáveis de cada experiência social permitem delimitar os sentidos que especificam cada manifestação cultural. ${ }^{7}$

O texto que resulta deste ensaio comparativo procura apresentar a experiência brasileira das delegacias da mulher e discute o que é feito neste âmbito por dois serviços de polícia canadenses, SPCUM e SQ. A nossa reflexão está organizada em três partes: na primeira são apresentados os dados de campo relativos à Delegacia da Mulher de João Pessoa; a seguir discutem-se sumariamente as experiências canadenses (Montreal) para que sejam confrontadas com as práticas no Brasil; finalmente, vem uma sistematização dos resultados obtidos e suas implicações em termos de políticas de promoção do acesso à segurança e à justiça no Brasil.

\section{Práticas policiais na Delegacia da Mulher em João Pessoa}

As delegacias da mulher são órgãos especializados da Polícia Civil criados em meados da década de 80 como política social de luta contra a impunidade e para dar atendimento mais adequado às mulheres vítimas de "violência conjugal" e crimes sexuais. Ao longo dos anos 80-90, elas foram sendo instaladas em todas as grandes cidades brasileiras. A primeira Delegacia da Mulher foi criada na cidade de São Paulo em 1985; dois anos depois, começou a funcionar a de João Pessoa, onde foi realizada a nossa pesquisa de campo.

A Delegacia da Mulher é instituição sui generis, setor especializado do serviço da Polícia Civil de cada Estado e é, tipicamente, polícia judiciária, o que equivale a dizer que ela atua como correia de transmissão entre os serviços de polícia e o sistema 
judiciário. O seu objetivo maior é, portanto, a instrução dos inquéritos policiais que levarão ao judiciário as queixas-crimes para julgamento.

Apesar dos muitos estudos que tomam como base as delegacias da mulher no Brasil, nos quinze anos que se seguiram à sua criação, a maioria das pesquisas parte dos registros do boletim de ocorrência, procurando levantar principalmente dados sobre "vítimas", "agressores" e tipos de crimes mais comuns. Os estudos sobre as práticas policiais no âmbito das delegacias da mulher, nosso objeto específico de estudo, são bastante raros e recentes, entre os quais se destacam os de Jacqueline Muniz (1996) ${ }^{8}$ e Bárbara Musumeci Soares (2000). Esse tipo de estudo é fundamental para a compreensão dos atendimentos prestados nas Delegacias da Mulher e do seu alcance, além de ser instrumento imprescindível para avaliar os serviços de polícia. ${ }^{9}$ A raridade dos estudos sobre as práticas policiais reside, sem dúvida alguma, na necessidade da observação direta e quotidiana que apenas pode ser realizada com a cooperação da delegada e das agentes policiais e com a concordância da queixosa.

Em resumo, convém lembrar que nossa pesquisa sobre as práticas policiais na Delegacia da Mulher começou em 1998, na $6^{\mathrm{a}}$ Delegacia de Florianópolis (SC). Foram realizadas entrevistas com a então psicóloga e policial Victória Regina dos Santos, responsável pela implantação de um projeto de atendimento psicológico naquela delegacia, e entrevistas com as delegadas que lá atuavam. ${ }^{10}$ Portanto, a pesquisa foi o resultado de longo processo de preparação teóricometodológico e de empatia até alcançarmos as condições especiais encontradas em João Pessoa, que descrevemos a seguir em suas grandes linhas.

\section{O trabalho da Delegacia da Mulher em cifras}

Tendo iniciado suas atividades em 1987, a Delegacia da Mulher de João Pessoa é a única do município que tem uma população de cerca de 500 mil habitantes. ${ }^{11}$ Funciona basicamente nos dias úteis das $8 \mathrm{~h}$ às $18 \mathrm{~h}$, fechando no horário de almoço. O número de atendimentos é bastante variável, sendo que no período de campo 
observou-se um máximo de 44 e um mínimo de 7, e uma média de 25 por dia. Tais atendimentos atingem a média anual de 1.460 registros no Boletim de Ocorrências.

\section{Gráfico 1 - Queixas registradas na Delegacia da Mulher de João Pessoa - 1995-1998}

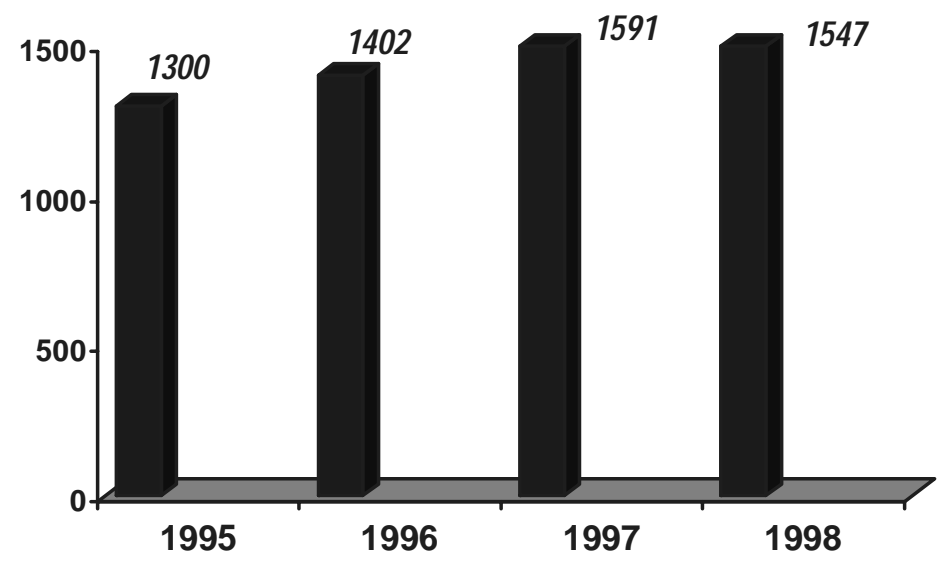

Na fase preparatória da pesquisa de campo em João Pessoa, havíamos constatado enorme discrepância entre os dados obtidos através dos registros do boletim de ocorrência e os encaminhamentos para a Justiça feitos através dos inquéritos policiais. Isso correspondia, no discurso dos setores ligados aos movimentos feministas, como 8 de Março e Cunhã, a uma avaliação negativa e prova da ineficiência da Delegacia da Mulher de João Pessoa.

Sem entrar nos dados já analisados em apresentações anteriores (Rifiotis, 1998, 2000a), lembramos aqui apenas as queixas registradas nos boletins de ocorrência e o número de inquéritos policiais instaurados entre 1995 e 1998 para que se possa ter uma idéia mais concreta da referida discrepância (Tabela 1). 
Tabela 1 - Boletins de ocorrência e inquéritos policiais instaurados na Delegacia da Mulher de João Pessoa - 1998

\begin{tabular}{|l|c|c|c|c|}
\hline \multicolumn{1}{|c|}{ Ano } & 1995 & 1996 & 1997 & 1998 \\
\hline $\begin{array}{l}\text { Registros no } \\
\text { Boletim de Ocorrência }\end{array}$ & 1.300 & 1.402 & 1.591 & 1.547 \\
\hline $\begin{array}{l}\text { Inquéritos Policiais } \\
\text { instaurados }\end{array}$ & $\begin{array}{c}46 \\
(3,5 \%)\end{array}$ & $\begin{array}{c}48 \\
(3,4 \%)\end{array}$ & $\begin{array}{c}35 \\
(2,2 \%)\end{array}$ & $\begin{array}{c}38 \\
(2,5 \%)\end{array}$ \\
\hline
\end{tabular}

À primeira vista, os dados levantados pareciam confirmar um grave problema no atendimento prestado pois, tratando-se de um serviço de polícia judiciária, a cada atendimento registrado no boletim de ocorrência corresponderia uma investigação que permitiria à autoridade policial buscar elementos para instaurar o inquérito policial e encaminhar o processo à Justiça, mas, entre 1995 e 1998, o percentual de registros transformados em inquéritos policiais não ultrapassou 3,5\% (Tabela 1).

A pesquisa de campo foi fundamental para explicar em parte a discrepância entre o número de registros de queixas e o de inquéritos. Desde os primeiros dias de trabalho de campo, observamos intenso fluxo de pessoas sem a devida correspondência entre esse número e os registros do boletim de ocorrência. Ao longo dos quatro meses de observação ficou evidente que tais números correspondiam a procedimentos genericamente previstos na rotina de qualquer delegacia, mas não expressavam o que de fato ocorria na Delegacia da Mulher. Além do mais, como discutiremos mais adiante, grande número de queixas registradas no chamado boletim de ocorrência não se caracteriza como queixa-crime, limitando o trabalho investigativo e prejudicando a instrução adequada dos inquéritos. Em outros termos, é preciso atentar para o fato de que os estudos realizados a partir do registro em boletim de ocorrência nem sempre remetem efetivamente a ocorrências policiais, e mesmo aquelas que se podem inscrever como crimes raramente são objeto de investigação, seja pela 
falta de pessoal e meios de investigação, seja pela urgência do atendimento quotidiano em detrimento do papel investigativo da Polícia Civil.

No decorrer do trabalho de campo, constatamos que os números em questão apenas poderiam ser corretamente interpretados quando comparados com o número de casos não registrados atendidos quotidianamente e que apenas a observação direta e contínua permite identificar e qualificar. ${ }^{12}$ Conforme discutimos ao longo de todo este trabalho, a peça chave das práticas policiais na delegacia da mulher é a intimação; assim somente comparando o número de intimações produzidas no mesmo período com os registros nos boletins de ocorrência é que podemos avaliar a especificidade do trabalho nessa delegacia especializada (Tabela 2).

Tabela 2 - Boletins de ocorrência, inquéritos policiais instaurados e intimações na Delegacia da Mulher de João Pessoa - 1995-1998

\begin{tabular}{|l|r|r|r|r|}
\hline \multicolumn{1}{|c|}{ Tipos de ação } & 1995 & 1986 & 1997 & 1998 \\
\hline $\begin{array}{l}\text { Registros no } \\
\text { Boletim de Ocorrência }\end{array}$ & 1.300 & 1.402 & 1.591 & 1.547 \\
\hline $\begin{array}{l}\text { Inquérito Policiais } \\
\text { instaurados }\end{array}$ & 46 & 48 & 35 & 38 \\
\hline Intimação & 2.861 & - & 2.700 & 2.576 \\
\hline
\end{tabular}

Assim, considerando a Tabela 2, pode-se concluir, em primeiro lugar, que o número de pessoas ouvidas foi mais do que o dobro das queixas registradas, pois em geral o atendimento começa com a própria queixosa no momento do registro. Aliás, geralmente a queixosa vem acompanhada por amiga ou parente, e não raramente há duas ou três pessoas com ela, o que demonstra o volume de trabalho das policiais na Delegacia da Mulher. Assim, em termos quantitativos, os 
atendimentos concentram-se basicamente na recepção de queixas, sem que elas se transformem em inquéritos, ou seja, o expressivo número de casos atendidos não corresponde ao número de casos qualificados para o encaminhamento judiciário.

As cifras expressam corretamente a insatisfação das policiais com o seu próprio trabalho e as críticas de representantes de organizações não-governamentais, como Cunhã e 8 de Março, e mostram de modo evidente que o princípio de judiciarização estrita não é prioritário. ${ }^{13}$ Resta saber como é efetivamente o quotidiano da Delegacia da Mulher, o que nos leva à etapa propriamente etnográfica da pesquisa.

\section{O quotidiano da Delegacia da Mulher}

Desde os primeiros trabalhos realizados em 1998 com as delegadas da $6^{a}$ Delegacia de Polícia de Florianópolis e com a psicóloga policial que lá atuava, já havia constado que o mecanismo básico daquela delegacia era o de criar as condições para a resolução de conflitos conjugais. Tal afirmação genérica está longe de descrever o conjunto de problemas e de demandas encaminhadas a esse tipo de delegacia e, para quem não vive a sua rotina diária, é difícil avaliar o tipo de atividade que efetivamente lá se desenvolve e a sua importância para as chamadas "clientes". Deste modo, na pesquisa de campo realizada em 1999 em João Pessoa, estávamos consciente das dificuldades do trabalho e dos limites da experiência etnográfica, mas convicto da importância de procurar nas práticas quotidianas os dados necessários para ampliar a nossa compreensão. Sem pretender tomar o caso da Delegacia da Mulher de João Pessoa como representativo, são levantados a seguir os dados de campo com vistas a uma descrição dos serviços prestados e do significado que the atribuem as "clientes".

Durante os quatro meses de trabalho de campo, estivemos diariamente observando os atendimentos realizados, entrevistando "clientes" e as duas equipes que atuam na Delegacia de Mulheres de João Pessoa. Assistimos a mais de setecentos atendimentos, 
envolvendo aproximadamente mil pessoas e que redundaram na metade de registros em boletim de ocorrência. Ouvimos relato de casos de briga entre vizinhos, entendimentos coletivos sobre herança, casos de profissionais do sexo agredidas, esposas proibidas por seus maridos de falar com os vizinhos ou de atender telefone, casos de estupro, com dominância da "agressão física", que é tipificada como "lesão corporal" nos casos mais graves. A variedade de tipos de casos certamente não representa uma especificidade da delegacia da mulher em relação às delegacias não-especializadas. Porém, o que nos parece ser o diferencial é a recepção concreta, de acolhimento dessas demandas. Isso é extremamente positivo do ponto de vista da qualidade do serviço policial, um dos seus mais importantes "produtos" (Rifiotis, 2000b).

A primeira constatação em campo que chamava a atenção era que a grande maioria das mulheres procurava espontaneamente a Delegacia da Mulher. Trata-se em geral de uma opção construída, uma preparação, realizada em muitos casos com a participação de uma vizinha, amiga ou parente. Porém, não raramente essas mulheres procuram os serviços de polícia sozinhas e, por vezes, trazem consigo seus filhos. Elas chegam e apresentam-se a uma atendente, que verifica se o caso é pertinente e se a mulher é maior de idade e residente no município de João Pessoa, caso positivo seu nome é anotado e ela é orientada a esperar com as outras até ser chamada e recebida pela delegada. Elas ficam então aguardando na sala de espera, onde episodicamente compartilham suas queixas e falam informalmente com outras agentes policiais, relatando seus "casos" e pedindo orientação.

O trabalho de observação concentrou-se inicialmente na "recepção", na entrevista com mulheres atendidas, no registro do boletim de ocorrência e nas entrevistas com as agentes policiais, a psicóloga e a assistente social, e sobretudo de observação das rotinas de trabalho. Foi neste processo que pudemos confirmar que a maioria dos registros do boletim de ocorrência não eram "ocorrências" a serem investigadas, mas relatos de cenas de conflitos intraconjugais. Somente após essa experiência de entrada, sentimo-nos preparado para aceitar 
o convite da delegada para acompanhar os atendimentos ao seu lado. A cada caso ela nos apresentava e pedia autorização para a nossa participação, o que resultou numa série importante de observações sobre as sessões de atendimentos que envolvem desde a chegada da queixosa, a intimação e acareação; muito raramente há instalação de um inquérito policial.

Para os objetivos desta apresentação, nos pareceu mais adequado descrever concretamente o nosso primeiro dia de observação acompanhando diretamente o trabalho da delegada de plantão. Os atendimentos relatados a seguir ocorreram numa única tarde, entre 15 e 18 horas. Foi um dia típico pelo que se observou no restante da pesquisa e traduz em termos concretos o quotidiano da delegacia.

O primeiro caso observado foi o de uma mãe que acompanhava sua filha menor de 21 anos. A mãe afirmava que ela iria pagar as despesas com o casamento, afinal ele [o "namorado"] sempre dizia que não tinha dinheiro para custeá-las. Ela resolveu pagar, porque, segundo ela, ele nem casa nem deixa a filha dela em paz. "A menina vive perseguida por ele..." É um caso que já vem se desenrolado há "muito tempo", ele inclusive já esteve na delegacia e se comprometeu a conseguir o dinheiro. "Agora o casamento sai", afirma a delegada, e confraternizam-se todos e com isso encerram o atendimento.

O segundo caso é apresentado pela agente policial como caso já atendido antes e que ela explica para a delegada nos seguintes termos: "Eles ao invés de entrarem em acordo..." Entram a senhora, que é mãe, sua filha e genro. A filha começa explicando, e falando pela mãe, afirma que o pai vendeu a parte dela da casa que tinham em comum. "Ligamos para o 190 e nada... Ele é velho e quer ir para o Rio de Janeiro e deixar tudo... Mas o pai começou a beber e tirou até as telhas... São os nervos". Seguindo a orientação da delegada, eles resolvem vender a casa e dar a parte do pai em dinheiro.

No terceiro caso, a mãe e filho pequeno. Ela narra que ela e a criança são espancadas pelo marido/companheiro e que a casa onde moram é dela. É a terceira intimação, mas ele não recebeu... Faz outra intimação... 
E, imediatamente, segue-se o próximo caso: um rapaz que pede que se chame a sua esposa para conversar porque estão brigando muito. Intima-se...

A agente de polícia entra e comenta que a ante-sala está lotada, e, enquanto passa ofícios para a delegada assinar, chama-se o próximo caso.

É uma menina que vem acompanhada da amiga. "Diga...", é a fórmula clássica da delegada para iniciar os atendimentos, ao que se segue um relato truncado que reproduzo a seguir: Ela mora na casa da irmã... Emprestou dinheiro ao irmão que não pagou... Ela está grávida de cinco meses. Foi pedir ajuda ao pai da criança que não quer assumir. Ela já tem outros dois filhos. Quando o irmão soube que ela foi procurar o pai da criança... "Apanhei grávida na rua! Não ia deixar por isso mesmo!!!” O cunhado jogou as coisas dela na rua, "mas a casa é da irmã...", diz ela. Ela quer o dinheiro emprestado para poder pagar um lugar para ficar. Solução: intimar a irmã e o cunhado para ver o que se poder fazer com ela. A jovem quer contar toda a história, dar outros detalhes, mas a delegada precisa só da frame...

O caso seguinte começa com uma jovem que entra e a delegada me explica em tom jocoso que nos instiga a curiosidade: ele veio porque ela ficou com uma foto do ex-namorado... Ela entra continuando uma narrativa que a delegada evidentemente conhecia e lembrava em detalhes, dizendo que foi roubada na Rodoviária que fica próxima à Central de Polícia onde está instalada a Delegacia da Mulher. Tinham acertado ontem, com o ex-namorado dela, que ele deveria pagar a ela os $\mathrm{R} \$ 13,00$ reais devidos e que ele só pagaria se ela devolvesse a foto dele... Ela vem declarar que ele pode ficar com o dinheiro... Ex-namorados, ele queria se separar mas ela não queria. Ela ficou com uma foto dele, que ele queria de volta..., por medo que ela "fizesse um trabalho" contra ele...

$\mathrm{O}$ atendimento seguinte é o desdobramento de um anteriormente atendido pela outra delegada que está de férias. Ela quer intimá-lo apenas para prejudicá-lo, diz ele, que vem acompanhado pela esposa 
atual, e afirma que a reclamante foi "só um caso". Ela quer dinheiro para comprar medicamentos receitados pelo médico. A esposa atual quer que a outra se retrate; discutem, mas o advogado que acompanha a "ex" afirma que ele continua a persegui-la e quer que os dois sejam intimados. A delegada lembra que não pode intimar porque não há queixa, mas o advogado explica que "já falaram com a outra delegada", ao que a atual responde: "então voltem dia tal... quando ela retornar ao serviço", e encerra o atendimento.

Mais dois casos serão atendidos antes de uma pausa. O próximo foi um engano, porque a mulher que entra abre a sua bolsa que contém visivelmente apenas um papel, que é a certidão da queixa prestada para ir à defensoria. Segue-se o caso da mulher que chega reclamando que a outra "disse que estou amancebada..., disse na frente de todo mundo". E, em seguida, completa: "Eu não quero que a senhora faça nada não com ela. Se for negócio de prender não quero. Não quero fazer mal a ninguém. Quero que dê conselho a ela.." Ela veio sem as duas testemunhas... Calúnia, difamação ou apenas retratação: "É mais fácil a senhora consertar", diz a delegada. Vão ser chamadas as testemunhas e ela vai se retratar.

O décimo caso "é sobre um irmão que eu tenho e inventa tudo sobre mim. Agora diz que vão tomar a menina de mim." É calúnia do ex-marido... Vai procurar duas testemunhas e voltará para ser efetivamente atendida, quer dizer, para registrar o caso no boletim de ocorrência e pedir que o irmão seja intimado...

Pausa. Foram 10 casos em quarenta minutos. Seguiu-se um momento em que a delegada confidencia que o problema crítico é quando as partes moram perto. "Se é vizinho eles se vêem todo dia..., mas como eles têm pouca cultura e acreditam que são impedidos de ir ao outro bairro..., quando eu digo para não verem mais a pessoa ("se a pessoa vem na rua, você mude de caminho"), eles cumprem. O mesmo vale para a intimação: "O simples fato de fazer uma intimação já tem efeito: quem recebe já sente o efeito, quem consegue já tem uma satisfação. Se não é problema da polícia, a coisa complica..."

Paramos a nossa breve conversa para que a delegada pudesse atender o próximo caso: eles são casados há dez anos, dois filhos. Os 
dois comparecem. Ela quer se separar... mas o que fazer se ele não sai de casa? "O que fazer? Ele deu para beber, assusta as crianças..." Já deram queixa dele e ele está na Justiça... A delegada esclarece que eles vão ter de morar juntos na mesma casa até o juiz decidir. "Outro dia ele chegou às 3 h da manhã com uns amigos, ligou o rádio...” Ela quer que a delegada diga a ele para não beber... que dê uns conselhos... A delegada esclarece: o caso é orientação de família; ela deve ir para a sala de atendimento psicológico para não ocupar a vez de outro que poderia estar sendo atendido...

Próximo caso: na festa da filha, ele bebeu e virou tudo. Ela quer marcar as visitas dele. A delegada assume o papel de conselheira: os filhos podem vê-lo na sala da casa, no final de semana. "Ele é PM", ela destaca, na intenção de ver se algo acontece. Enquanto a delegada insiste que ele não deve entrar na casa sem a permissão dela, que o comportamento dele é prejudicial às crianças..., e conclui com seu bordão clássico: "Tá combinado assim? Tá certo? ... Então, tchau." Num tom autoritário, ela procura selar o frágil pacto celebrado às pressas.

Entra na sala um PM com mulher chorando. Mas logo entendese que o caso é da Especializada de Roubos e Furtos que fica ao lado, pois trata-se na verdade de uma acusada de roubo. Entra um policial civil que leva a mulher e discute com o PM: "é assalto, o caso...". Saio para ver. Ela é puxada pelo cabelo por outro policial da Roubos e Furtos e é empurrada num sofá onde está sentado um homem, supostamente seu "comparsa"... O clima é tenso, cheio de agressões, falatório, indignação... Uma policial explica em tom de confidência que eles devem estar discutindo umas "paradas"... Um policial vem à Delegacia da Mulher pedir que uma agente vá revistar a mulher detida. "É perigoso... se ela tiver uma gilete...", diz a policial que sai para a revista.

Continuam chegando pessoas; as intimações continuam sendo um problema-chave. As pessoas não têm endereço, não sabem o número da casa, às vezes nem o nome da rua... Vão embora para trazerem o endereço no outro dia... 
Observo que a jovem que está grávida e vai ser expulsa da casa da irmã pelo seu cunhado, apesar de já ter sido atendida há mais de uma hora, ainda está na sala de espera falando com a atendente. Ela não quer que a irmã e o cunhado sejam intimados porque ela crê que isso seria motivo para ele abandonar a irmã... Essa narrativa confusa é interrompida pela agente policial que dá o seu vaticínio: "Antes de fazer neném, é meu piteuzinho para cá, meu amor, meu xodó. Depois..." Este é um exemplo paradigmático da complexidade dos casos atendidos. Na realidade, entedemos depois que a jovem grávida deseja continuar na casa da irmã até o nascimento do filho. Ela preferiria que fosse intimado o irmão que a ofendeu na frente de todo mundo e lhe deve $\mathrm{R} \$ 400,00$, pois, sempre segundo ela, com este dinheiro ela compraria um quarto e ficaria bem. Mas, a agente corrige a jovem dizendo que a delegada não pode "chamar" o irmão por esse motivo...

Discute-se sobre uma faca que era peça de inquérito e a necessidade de cooperação da equipe. A delegada segue conversando enquanto a jovem que quer intimar o irmão quer explicar novamente o caso... Fala-se da síndrome da $2^{\text {a }}$ feira, dos problemas de família, da bebida e aparece todo um rol de julgamentos sobre a "clientela" da delegacia. A bebida é presença constante e, às vezes, parece autoexplicativa, e mesmo justificativa. Nessas conversas aprendemos que as duas psicólogas só vêm pela manhã quinta e sexta... Aliás, a psicóloga não tem vindo ultimamente porque está trabalhando temporariamente em outra atividade..., mas logo explicam que ela não pertence ao quadro da Secretaria de Segurança Pública, é contrato provisório...

No final do dia, chegou uma senhora que nos contou o seu caso. Ela vive com duas filhas, o pai foi abandonado pela mãe que casou com rapaz de vinte anos. $\mathrm{O}$ pai se desesperou, foi morar com ela, bebe e está infernizando a sua vida. Ela compra cigarros para ele... A delegada já havia atendido os casos relacionados pela atendente e já não está mais presente. 


\section{Apropriação da Delegacia da Mulher por parte da clientela}

Sabe-se que nem todas as vítimas procuram a Delegacia da Mulher, e que geralmente não o fazem após a primeira agressão. A tomada de decisão é longa, complexa e conflitiva. Muitas vezes, para tomar a iniciativa de procurar o apoio da polícia, dependem do apoio de parentes, amigos, vizinhos e de médicos que as atendem. $\mathrm{O}$ problema é que as mesmas pessoas que poderiam ser importantes para tal decisão podem ser aquelas que, por omissão ou até mesmo conivência, não lhe prestam o apoio necessário. É preciso ter em conta que a ação policial se dá nesse campo eivado de conflitos e dilemas.

“É ela de novo!" é expressão que se ouve quando retorna uma mulher já vitimizada e atendida anteriormente na Delegacia da Mulher. Cada caso é um caso, ninguém se cansa de repetir, mas a recorrência dos relatos os fazem semelhantes uns aos outros e todos parecem uma mesma história inscrita numa série tragicamente previsível. A impaciência que denota essa frase não é necessariamente explicitada durante o atendimento, mas deixa entrever uma visão negativa sobre a vítima.

As agentes policiais da Delegacia da Mulher sabem muito bem qual combinação estará na base dos casos atendidos às segundas-feiras: final de semana, álcool, pobreza e agressão. Uma equação crua, simplista e, sobretudo, preconceituosa, mas que é - em graus variados - plenamente verificada no quotidiano das delegacias da mulher. Assim, o problema não está na existência ou não desses casos, mas na sua interpretação, que pode ser limitada e preconceituosa, confundindo as características dos casos considerados como suas causas. Afinal, prevalece a lição: o que nos é familiar não necessariamente nos é conhecido. $^{14}$

Para que se tenha um quadro mais completo sobre os limites da sua atuação é preciso ter em conta também que, na grande maioria dos casos, a Delegacia da Mulher é procurada após uma série de agressões, que geralmente voltam a reproduzir-se, numa série que parece não ter fim. Trata-se de trabalho muitas vezes considerado morto, perdido. $\mathrm{O}$ que mais incomoda as agentes policiais é a sua 
impotência diante dos casos de violência conjugal. Esse fenômeno começa e se desenvolve de modo invisível para elas, e quando ganha dimensão policial, ainda assim não está completamente a seu alcance. A vítima pode retirar a queixa, nos casos previstos pela lei, e transformar todo um trabalho de investigação, quando efetivamente existe, e de tomada de depoimentos, em trabalho morto. Essa frustração é marcante para a caracterização da auto-avaliação das delegadas, e mostra a diferença entre a auto-identidade da instituição (polícia judiciária) e a identidade atribuída pela "clientela".

Outro aspecto marcante nos atendimentos das delegacias da mulher é a utilização do poder de polícia - através do mecanismo da intimação - para reordenar as relações de poder no espaço doméstico. O cenário é o seguinte: após denunciar, por exemplo, uma agressão, a reclamente pede que a delegada chame o seu marido para conversar, para que ela lhe dê um conselho, um susto... A atividade de polícia judiciária é constantemente substituída por uma demanda de ordem privada. No limite, parece que, do ponto de vista policial, haveria uma espécie de manipulação secundária da delegacia por parte da reclamante, que procura valer-se da autoridade policial para obrigar o seu agressor a admitir o erro e a renegociar a relação entre eles. A intimação é ressignificada como intimidação.

As filas de espera para atendimento, as discussões em torno do endereço para entrega das intimações, a multiplicação das narrativas, as demandas de acertos privados com mediação policial, a opção pela retirada da queixa, a reprodução dos casos, todos são fatores que têm levado os agentes policiais a se perguntar sobre o papel, e até mesmo sobre a validade do seu trabalho nas delegacias especializadas. Além disso, a experiência tem mostrado que a centralidade policial nos procedimentos prestados nas delegacias da mulher é considerada insatisfatória pelas vítimas, que às vezes reclamam, também, uma ação judicial e, outras vezes, um atendimento que é chamado de "aconselhamento".

Sem excluir a realização de importante e altamente valorizado atendimento às mulheres vítimas de crimes, o que foi constatado exige 
que se reconsidere o papel efetivamente desempenhado pela delegacia da mulher. De modo geral, pode-se afirmar que para a "clientela", a delegacia é valorizada como espaço público informal de controvérsia no qual podem contar com a participação de uma autoridade policial, cujo papel é central para as "clientes". Atuando como conselheira ou fazendo o que chamaria "mediação policial", ${ }^{15}$ a delegada é certamente o eixo em torno do qual todas as atividades são realizadas. Nesse contexto, assim como evidenciou Jacqueline Muniz (1996), "entrar na justiça" é visto de modo negativo e não como equivalente a "fazer justiça". Trata-se de uma questão da maior importância, pois a delegacia da mulher é instituição da polícia judiciária, criada para atuar como mecanismo de controle social, mas que vem sendo reorientada para atender demandas diversas, tornando-se recurso social tipicamente de controvérsia e regulação informal de conflitos interpessoais.

\section{Experiências canadenses: província do Quebec e município de Montreal}

Seguindo o objetivo proposto para este trabalho, passamos agora a apresentar em grandes linhas a política social desenvolvida pelos serviços de polícia da província do Quebec e da cidade de Montreal, no Canadá, para fins comparativos que nos permitam colocar em evidência a especificidade da experiência brasileira da delegacia da mulher.

Inicialmente, deve-se destacar que, em meados dos anos 80, houve uma reorientação geral do trabalho policial no âmbito da "violência conjugal", não apenas no Canadá e nos Estados Unidos, mas também em outros países. A própria categoria "violência conjugal", como lembramos no início deste trabalho, tem natureza ao mesmo tempo local e global. A sua transformação em categoria de âmbito público foi fenômeno histórico da maior significação, assim como a adoção de medidas jurídicas e policiais específicas. Reconhecem-se três possibilidades básicas nesses casos: aconselhamento do casal, separação do casal e prisão do agressor. 
A última destas é representada pelo movimento pró-detenção, tipicamente experimentado nos EUA e analisado em detalhe nas suas múltiplas facetas e diferentes conseqüências. Sem dúvida, The Minneapolis Police Expriment (Sherman \& Berk, 1984) é referência obrigatória neste campo. Porém, as suas conclusões sobre o impacto da reincidência, ${ }^{16}$ que seria menor em caso de detenção do que de separação, foi relativizada na revisão de várias experiências realizadas nos EUA a partir do caso de Minneapolis, em posterior publicação de Lawrence W. Sherman (1992):

1) a detenção atuaria de modo seletivo e temporário em termos de classe social e pertença étnica e cultural;

2) dificuldade de encontrar um meio efetivo de prevenir a reprodução crônica da "violência conjugal";

3) detenção como meio exclusivo de luta contra a "violência conjugal" mostra o quanto se abandonam os outros meios e se desconsidera o seu caráter social;

4) seria preciso levar em conta a diversidade social e a adaptação das políticas.

Sem retomar aqui as discussões em torno das experiências desenvolvidas no Estados Unidos, por estarem fora dos limites impostos a nosso trabalho, entendemos necessário lembrar que o impacto da detenção do pressuposto agressor deve ser nuanceada, e que o próprio Sherman relativiza o alcance dessa política, apontando o seu caráter seletivo (classe social ou grupo étnico). Neste sentido parece haver uma tendência de diminuição do poder discricionário e correlato aumento da formação específica e da responsabilização profissional do policial e dos serviços de polícia. ${ }^{17}$

Concentrando nossa atenção no caso do Quebec, é interessante lembrar que, em 1985, o Ministério da Saúde e dos Serviços Sociais adotou a Política de apoio às mulheres violentadas. No ano seguinte, uma política específica foi definida pelo Ministério da Justiça e pelo Ministério da Segurança Pública (oriundo do Ministère du Solliciteur Général) em termos de "violência conjugal", fazendo entrar em cena 
serviços de polícia, de justiça e prisionais. Tratava-se de afirmar o caráter criminal dos atos de violência cometidos no contexto familiar.

A base da política de intervenção do governo do Quebec nos casos de "violência conjugal" está assentada em três princípios: prevenir, revelar (dépister) e intervir com apoio psicossocial, judiciário e prisional, ${ }^{18}$ Trata-se de um conjunto de medidas e de incentivos aos trabalhos sociais e não apenas um trabalho policial e judiciário. Assim, tem-se a assinatura de protocolos específicos de ação como aqueles entre o SPCUM e os CLSC, ao longo dos anos 90, em Montreal, nos quais são definidas as atividades conjuntas e responsabilidades específicas de cada setor. O objetivo do protocolo é fornecer às vítimas de "violência conjugal" serviços complementares entre os atendimentos médico e policial, ${ }^{19}$ como tem sido feito na experiência do protocolo de violência sexual em Santa Catarina, iniciado em 2001.

O SPCUM define através de uma diretiva específica a atuação dos policiais em casos de "violência conjugal", tipificando a matéria, definindo o papel do policial e suas responsabilidades, e detalhando os modos de ação. O texto da diretiva é bastante detalhado, regulamentando concretamente a atividade policial e modos de proceder em termos de atendimento à vítima, encaminhamento consentido aos serviços de saúde e procedimentos técnicos para a investigação policial. A diretiva policial de ação nos casos de "violência conjugal" é conhecida pelo seu número, 501-5, criada em 1994, modificada em 1995, e redefinida em 1999, assumindo o número 249-2. A modificação mais evidente se deu na troca de termos como "crime" e "agressor" por "infração" e "suspeito"; além disso, na versão de 1995 aparece a menção explícita de que o "agressor" deve ser detido quando a segurança da vítima estiver ameaçada. Em resumo, trata-se de definir concretamente o objeto específico da intervenção, os papéis e responsabilidades do policial e do investigador. $^{20}$

No contexto de Montreal, é fundamental compreender que a política sobre "violência conjugal" foi implementada a partir de 
amplos debates para a definição do papel dos serviços de polícia para proteção das mulheres vitimizadas. ${ }^{21}$ Além disso, houve um período de formação dos policiais na matéria, que atualmente faz parte do currículo da formação dos futuros policiais, como constatado em pesquisa no Collège Maisonneuve de Montreal, com o professor Pierre Brisebois. ${ }^{22}$

Apesar do quadro favorável ao desenvolvimento de uma política de intervenção no Canadá, os problemas enfrentados pela polícia são comparáveis àqueles encontrados no Brasil. De fato, no nosso trabalho de campo no Poste de Quartier 25 (PQ 25) de Montreal, nas entrevistas realizadas com policiais e nas discussões com pesquisadores do Centro Internacional de Criminologia Comparada da Universidade de Montreal, pudemos constatar que a situação estava apenas aparentemente resolvida. De fato, tanto os policiais entrevistados como os pesquisadores canadenses nos fizeram ver que havia problemas que mereceriam uma análise mais acurada. Assim, o trabalho de campo no PQ 25 mostrou, por exemplo, que os policiais consideravam a "violência conjugal", que chamavam de "VC", como problema sem solução e se sentiam insatisfeitos com a reação das vítimas, a falta de seu apoio para a punição dos agressores, a ambigüidade desse tipo de caso. As entrevistas realizadas com vários policiais revelaram o descontentamento com seu trabalho, considerado muitas vezes, a exemplo dos nossos entrevistados no Brasil, como trabalho morto ou inútil, classificado na delegacia da mulher como "enxugar gelo".

Dada a complexidade da situação, a atuação policial foi reforçada pela aproximação com o judiciário. Na Corte de Montreal, os casos de "violência conjugal" passaram a ter tratamento específico a partir da edição do Artigo 810, que regulamenta as limitações a que deve ser submetido o "agressor". Com a edição desse artigo pretendia-se evitar a prisão sistemática em casos de "violência conjugal", criando-se um mecanismo de controle sobre o comportamento dos agressores. Concretamente, trata-se de instrumento legal aplicado em casos de "violência conjugal" para definir limites de aproximação entre a pessoa vitimizada e o vitimizador após a detenção deste, para garantir a segurança das vítimas. $^{23}$ 
Sumariamente, destaco aqui os aspectos que nos pareceram relevantes para um primeiro esboço comparativo internacional das práticas policiais no âmbito da "violência conjugal". A questão é considerada tão complexa que a ninguém parece chamar a atenção que se tenha criado uma Divisão de Agressões Sexuais na SPCUM, mas nada análogo em caso de "violência conjugal". Para o pesquisador da realidade brasileira, a experiência de pesquisa no Canadá aparece como situação paradoxal, pois apesar da multiplicidade de meios públicos, estatais e não-governamentais disponíveis, a avaliação dos resultados parece ficar sempre abaixo do desejado.

\section{Comparando e especificando}

O fato do feminismo ser um movimento social global é uma obviedade que merece ser analisada com mais atenção, assim como os seus impactos sobre a construção de categorias como a "violência conjugal" e suas implicações na definição de políticas públicas e de investimentos do Estado neste campo, e, sobretudo, na promoção e na garantia da cidadania das mulheres.

Nos estritos limites impostos a este trabalho, as diferenças entre as abordagens dadas pelo SPCUM em Montreal e pela Polícia Civil em João Pessoa no âmbito da Delegacia da Mulher são muito importantes. De fato, contextos culturais e históricos diferentes, estruturas jurídicas e policiais diversas, organização e oferta de serviços públicos sem comparação, etc. são respostas sociais que expressam diferenças locais. Porém, para além da coincidência das datas em que as medidas no âmbito da "violência conjugal" são adotadas, a busca de regulação com a utilização de mecanismos jurídicos e especificamente policiais são uma constante. Além do mais, são características comuns os dilemas, ambigüidades e contradições identificadas com as vítimas de "violência conjugal".

No Brasil, por demanda da própria sociedade, o Estado criou as delegacias especiais voltadas ao atendimento de mulher, crianças e idosos para minimizar os trágicos efeitos da violência intrafamiliar. 
Os membros das famílias que procuram os serviços dessas delegacias poderiam optar por resolver os conflitos domésticos nessa instância; porém, tem-se observado que ela é utilizada apenas como apoio: uma peça a mais no complexo jogo da resolução dos conflitos privados. ${ }^{24}$

$\mathrm{O}$ atendimento de demandas que não correspondem à identidade institucional da Polícia Civil nas delegacias da mulher está no centro da discussão sobre a "mediação policial" e da definição do que pode ser considerado "público" e "privado" e qual o espaço atual da delegacia da mulher no campo privado. Isso depende não apenas da vontade da vítima, mas da definição jurídica de direito público e direito privado.

Em resumo, também os fatos aqui relatados são óbvios e, de tão evidentes que são, a sua real dimensão pode passar despercebida. Muitas vezes esses problemas são considerados internamente apenas como erro grosseiro de procedimento, falta de experiência ou má preparação dos policiais. Nossas pesquisas têm mostrado que esse ponto de vista é mais comum entre oficiais ou delegados do que entre soldados e sargentos ou agentes policiais. É comum entre os policiais ditos "de rua", aqueles que se consideram mais próximos do "fazer polícia”, ouvir este tipo de avaliação. ${ }^{25}$ Está-se frente a um dado importante da formação do policial como membro de uma comunidade, com a qual ele compartilha seus valores. Trata-se de uma percepção, um automatismo que não pode simplesmente ser negado, pois mais do que traço cultural de um agente considerado isoladamente, ele faz parte do universo cultural de um conjunto de agentes como membros de uma sociedade. Como se mostra na segunda parte deste texto, para mudar esta percepção precisamos saber que não se trata de simples questão de certo ou errado, mas de valores a partir dos quais se vê a realidade e sobre os quais se contrói a própria identidade.

No âmbito da delegacia da mulher, a polícia não pode ser considerada como simples correia de transmissão entre os conflitos intrafamiliares e o campo jurídico. Aliás, isso já vem acontecendo, tanto no que se refere às demandas que enfrentam as delegacias da 
mulher, como pelas práticas policiais que delas decorrem. Assim, estaria ampliando nossa perspectiva do fenômeno e construindo uma posição mais consciente, levando-nos a uma intervenção mais adequada. A ação policial nos casos de violência intrafamiliar é uma mediação social no interior de relações sociais privadas. ${ }^{26}$

O que distingue a experiência brasileira é, sem dúvida, o formato de uma delegacia especialmente dedicada ao atendimento de mulheres, em vez de diretivas específicas. Na realidade, esse tipo de instituição existe também no Peru, onde é ligada ao Ministério da Justiça. Foi criada em 1988 e regulamentada em dezembro 1993 pela Lei 26.260, que aprova as normas sobre a política de Estado e da Sociedade frente à violência familiar e criação das Comisarías de Mujeres, também chamadas Delegaciones de Mujeres.

A percepção da psicóloga entrevistada é de que as "clientes" não procuravam a delegacia em busca de uma ação jurídica mas, antes, buscavam a solução de conflitos fora do âmbito jurídico, o que expressam em pedidos tais como chamar o companheiro para "dar uma prensa", "dar um susto" etc., ou simplesmente para uma orientação - "saber dos direitos"- sem que isto implicasse a sua utilização concreta. Trata-se de uma demanda extrajudicial em que se procede conforme uma etiqueta e regras talhadas na informalidade e no "bom-senso", por vezes independentemente do caso ser de "crime de ação pública” (Muniz, 1996, p. 135).

De modo geral, os processos abrem o espaço privado, tornando pública a vida pregressa do acusado e da vítima. Decodifica-se, através de uma avaliação dos atos dos envolvidos, o desempenho e o ajustamento ao desempenho de papéis sociais ("bom pai” ou "bom filho", por exemplo), extraindo-se deles as razões que condenam ou absolvem. Assim, os dilemas entre a moralidade pública e a moralidade privada são explorados para a construção da verdade jurídica.

Por outro lado, especificamente sobre as questões ligadas à nossa análise da delegacia da mulher como política pública com atuação sobre o universo de relações de intimidade e afetividade, 
ditas "privadas", impõe-se uma consideração teórica, mesmo não sendo nosso objetivo, sobre a noção de público e privado. Pode-se afirmar hoje que há concordância em torno da idéia de que a dicotomia privado/público é simplificadora. Porém, parece-nos que tal constatação pode levar-nos a uma simples negação ou até o abandono dessas noções se não levarmos em consideração que a dicotomia entre público e privado tem assumido diferentes formas conforme o contexto histórico e que ela ainda é um "instrumento poderoso de legitimação" (Brodeur, 1995, p. 144). Assim, estamos em pleno debate da complexidade e das novas configurações da relação público-privado e a judiciarização do quotidiano, o que abre um capítulo da maior significação social e teórica para os estudos da sociedade contemporânea.

O aumento da demanda de mediação pública nos conflitos intrafamiliares e as críticas à "mediação" homogeneizadora e criminalizante apontam para um caminho em direção a novas formas de mediação, como as "casas da cidadania", em processo de instalação no Estado de Santa Catarina. Estes processos parecem revelar não uma volta à privatização do mundo doméstico, mas uma nova relação entre as instâncias do "público" e do "privado". ${ }^{27}$ Há uma indicação neste sentido mesmo nas mudanças legais como a instituição do Termo Circunstanciado, pois ele permite que nos casos específicos haja um acordo, um compromisso estabelecido por e entre as partes. Nesse caso, a delegacia pode atuar como depositária daquele documento e zeladora do seu cumprimento.

Finalmente, parece-nos fundamental discutir o papel das delegacias da mulher e sua relação tutelar em relação às mulheres. Em especial no casos de violência intrafamiliar em que a vítima é uma mulher adulta, pois a sua condição de maioridade - ao contrário da criança - faz dela um agente com opção pessoal e jurídica. A reação dos policiais diante da criança e da mulher adulta vitimizadas não é a mesma, e exigir que ela "assuma seus atos" como está pressuposto nos atendimentos observados, coloca-a numa situação de menoridade. Assim, deve haver nova preparação para que as policiais possam atuar eficientemente nesses casos, apoiando e esclarecedo as vítimas, mas sempre procurando respeitar a sua capacidade de decisão. 
A experiência de cada delegacia da mulher segue processos e dinâmicas diferentes, nem sempre comparáveis para além da esfera genérica da atividade de polícia judiciária. Em conclusão, levantamse a seguir quatro aspectos da delegacia da mulher que parecem fundamentais para a compreensão dessa instituição no que se refere ao acesso à justiça e ao seu papel concreto como mecanismo de judiciarização de conflitos interpessoais, especialmente aqueles chamados de "violência doméstica".

a) A delegacia da mulher é um recurso coletivo de transformação de conflitos interpessoais, envolvidos numa rede complexa e ambígua de elementos de ordem afetiva (paixão, amor) que se cruzam com corpos machucados, dívidas, projetos e interesses pessoais. A delegacia da mulher é um operador coletivo de reordenamento de conflitos e seus dilemas em categorias aceitáveis socialmente e eventualmente, cujo horizonte é o campo jurídico, ainda que não seja seu objetivo.

b) A elegacia da mulher é um espaço público de controvérsia, onde se dá um reordenamento de relações interpessoais baseado na autoridade policial. Na realidade, é a confiança no poder discricionário da delegada como agente capaz de contribuir ou mesmo de ser instrumento do reordenamento da vida privada.

c) Nos casos do que se costuma chamar "violência conjugal", a delegacia da mulher torna-se um espaço de dramatização de conflitos e de reconhecimento da culpabilidade que pode garantir a continuidade da vida conjugal.

d) A delegacia da mulher é um espaço de palavra, de escuta, onde a denúncia permite objetivar a crise da relação conjugal tirando o seu caráter singular. A objetivação se faz tornando pública a relação e seus conflitos e dilemas, tendo a figura da autoridade policial como testemunha e com força para definir o "retorno ao bom caminho". 


\section{Notas}

1 A pesquisa que originou este texto foi realizada com o apoio do CNPq, e o trabalho de campo foi realizado em João Pessoa durante o período em que atuamos como professor visitante da CAPES no Programa de Pósgraduação em Sociologia da Universidade Federal da Paraíba.

Cabem aqui agradecimentos especiais às delegadas e à equipe da Delegacia da Mulher de João Pessoa pela cooperação inestimável na realização do trabalho de campo, assim como ao intercâmbio entre o Laboratório de Estudos das Violências (LEVIS) da Universidade Federal de Santa Catarina com a Professora Maria Nazareth Zenaide e Lúcia Lemos, da Coordenação de Projetos de Ação Comunitária da Universidade Federal da Paraíba, que nos possibilitaram participar em vários eventos e cursos com as equipes das Delegacias da Mulher, bem como no Centro de Ensino da Polícia Militar daquele Estado.

2 Em muitas ocasiões, ao longo dos quatro meses de convívio quotidiano, as policiais afirmaram que havia enormes diferenças do seu trabalho com o de outras delegaciais. A diferença foi expressa por uma policial em termos de uma "humanização da delegacia", explicada como especificidade do trabalho das mulheres policiais.

3 Aquele momento foi de grande riqueza pelas atividades que mantivemos na Universidade Federal da Paraíba como professor e participante do Grupo de Pesquisa em Gênero do Núcleo de Documentação e História Regional (NDHIR), da Comissão dos Direitos Humanos da UFPB e atividades conjuntas com o Conselho Estadual de Defesa dos Direitos do Homem e do Cidadão. As trocas que se estabeleceram então foram decisivas para o rumo dos trabalhos e contribuíram de modo muito significativo para o nosso crescimento intelectual.

4 O atendimento psicológico na Delegacia da Mulher foi objeto de reflexão específica realizada em parceria com Victória Regina dos Santos, responsável pela implantação do antendimento familiar na Delegacia da Mulher de Florianópolis, apresentada no X Congresso Internacional de Vitimologia (Montreal, 2000). Naquele trabalho discutimos os limites e o significado do atendimento psicológico baseado no uso da intimação para a sua realização.

5 A nossa experiência no Canadá foi enormemente enriquecida com o trabalho em diversos setores da SPCUM e SQ. Agradecemos aos responsáveis de tais setores e ao pessoal que pacientemente aceitou ser entrevistado ou permitiu a observação direta do seu trabalho. Foi sua generosa acolhida e colaboração que viabilizaram a nossa entrada no 
universo policial canadense, em especial na temática da "violência conjugal". A abertura para a observação participante no Poste de Quartier 25, junto ao Sargento Eric LaPenna, foi fundamental para dar à reflexão teórica uma dimensão vivencial sobre o modelo de polícia comunitária e o atendimento nos casos de conflitos intrafamiliares. Destacamos igualmente a colaboração de Pierre Brisebois, policial aposentado e professor de Técnicas Policiais, que nos facultou o acesso ao ensino simulado e aos métodos de formação do Collège Maisonneuve, instituição que prepara candidatos para a carreira policial.

6 Processo complexo que não se limita à "violência conjugal", a "judiciarização" traduz duplo movimento: de um lado a ampliação do acesso ao sistema judiciário, e por outro, a desvalorização de outras formas de resolução de conflito.

7 Com relação às dificuldades do método comparativo, assumimos aqui a mesma postura adotada por C. Geertz na sua análise da Antropologia do Direito: “(...) é através da comparação, e de incomparáveis, que compreenderemos seja qual for o coração a que conseguirmos chegar" (Geertz, 1998, p. 354).

8 O trabalho de Jacqueline Muniz (1999) descreve a contradição de expectativas entre a lógica legal e a das pessoas atendidas nas delegacias da mulher, mostrando um aspecto fundamental dessa instituição, que é a centralidade da negociação de conflitos conjugais, basicamente realizada através do mecanismo de "chamar para conversar" ou "dar conselho".

9 Sobre a avaliação dos serviços de polícia publicada em dois trabalhos no Bulletin "La police dans les sociétés démocratiques," do Centre de Recherche et d'Enseignement sur les Droits de la Personne, da Universidade de Ottawa (Rifiotis, 2000c, 2000d).

10 As entrevistas na Delegacia da Mulher de Florianópolis foram realizadas por Daiane Roman (LEVIS/UFSC), sob a nossa orientação. Esse material foi enriquecido com as entrevistas realizadas com a agente policial e psicóloga Victória Regina dos Santos, atualmente concluindo mestrado no Programa de Pós-Graduação em Antropologia Social/UFSC e pesquisadora do LEVIS.

11 Em 1998, havia outras sete delegacias da mulher no Estado da Paraíba.

12 Durante o trabalho de campo sugerimos que o registro de chamada para atendimento na ordem de chegada, que era feito no verso de folhas de papel avulsas, fosse transformado em caderno específico, independente do boletim de ocorrências. Isso não trouxe acréscimo de trabalho e permitiu registrar o volume de atendimentos realmente realizados. 
13 Por essa razão os cálculos baseados no boletim de ocorrência representam fonte muito problemática para o conhecimento do trabalho da delegacia da mulher e da leitura de tendências de crimes, pois, além do mais, tratase nessa fase de uma denúncia que deveria ser investigada para compor inquérito policial que indicaria a existência de elementos para o encaminhamento à justiça.

14 Como no caso das estruturas lingüísticas: não é necessário que se conheçam as regras gramaticais para falar e se comunicar. $\mathrm{O}$ falante sabe utilizar os mecanismos lingüísticos, sem conhecer as suas regras e estruturas.

15 Em oposição ao procedimento que exige autonomia das partes e participação de um terceiro neutro, o mediador, que auxilia as partes a encontrarem suas próprias soluções para transformar determinado conflito.

16 A rigor, a própria noção de "reincidência" que a ação policial deveria limitar é apenas um fato jurídico, pois generaliza a idéia de que a "violência conjugal" inscreve-se sempre numa série e raramente é percebida e denunciada como tal numa primeira vez.

17 The case Thurman: 2,3 milhões de dólares de indenização por falta de resposta policial a um caso de "violência conjugal" (Buzawa \& Buzawa, 1990).

18 Resumo interessante dessa política encontra-se na publicação Prévinir, dépister, contrer: la violence conjugale (1995).

19 É importante destacar que os serviços médicos têm papel importante nesse processo e que nem sempre a sua contribuição é considerada positiva: «L'attitude des policiers est généralement perçue par les femmes comme étant plus positive que celles des médecins. En fait, $41 \%$ des femmes qui ont fait appel aux policiers qualifient leur attitude de 'positive', et près du quart (23\%) la jugent 'correcte'. » (Rinfret-Raynor \& Cantin, 1999, p. 15).

20 A definição da intervenção começa com um sumário concreto do que o policial deve entender como "violência conjugal": "asssédio, intimidação, ameaças, agressão ou uso de violência física ou psicológica contra a pessoa do seu cônjuge, cônjuge de fato ou ex-cônjuge, seu namorado ou exnamorado, quer ela seja do sexo oposto ou do mesmo sexo". Cabe esclarecer que a diretiva é uma espécie de manual de instruções cujo objetivo é normalizar a ação policial tanto no aspecto formal e legal como no espírito da intervenção específico para esse tipo de atendimento, limitanto assim o poder discricionário e tornando o atendimento mais eficiente e eficaz. 
21 Ver documento "Politique en matière de violence intra-familiale et conjugale", que orientou debate sobre essa matéria (s.e., 1993).

22 Pesquisa feita no início desse processo com policiais de Montreal revelou que eles se consideravam despreparados e desarmados para atuar nos conflitos conjugais (Baril, Cousineau \& Gravel, 1983).

23 Em pesquisa ainda em andamento, Sonia Gauthier (2000) estudou a aplicação do Artigo 810 em Montreal e descobriu que, ao contrário da sua expectativa, raramente o "agressor" era detido nos casos de "violência conjugal".

24 Pesquisa coordenada pela professora Guita Grin Debert em Campinas e em São Paulo, sobre as Delegacias de Proteção ao Idoso, mostra que raramente o idoso é vitimizado por um desconhecido, e que a retirada da queixa e o pedido de um aconselhamento para o agressor também marcam o atendimento prestado (Juvêncio \& Baptista, 1996).

25 "Fazer polícia" é uma expressão corrente no meio policial e significa uma marca distintiva entre o trabalho valorizado e outras atividades consideradas menores, o que é particularmente importante para o caso das delegacias da mulher, que parece estranha ao papel típico da profissão, que seria para os policiais o cambate ao crime, a investigação e a detenção. Assim, um aspecto que não deve ser negligenciado para o desenvolvimento do atendimento específico para os casos de violência intrafamiliar é a avaliação interna diferenciada entre as delegacias distritais e as especiais, e a distribuição de responsabilidades.

26 Sobre a temática da "mediação policial" na violência intrafamiliar nos valemos da exposição de Éric Plaisant, publicada no periódico Les Cahiers de la Sécurité Intérieur, n. 28, 1997.

27 Na realidade, trata-se de questão complexa e que demanda estudos mais específicos. Agradeço a Guita Grin Debert pelos seus comentários a este texto e por ter dado acesso ao seu paper intitulado "Políticas Públicas e o Direito à Diferença: as delegacias especiais de polícia" (2001), que nos ajudou a pensar na revalorização da família como interlocutor nos procedimentos policiais e seu papel como aliada para a execução de políticas sociais. 
Abstract: Social movements that fight against impunity in cases of "conjugal violence" are, at the same time, local and global movements whose transversal dimension represents a great challenge and shows the need for comparative research among local solutions. The Women's Police Department is a dispositif of the judiciary police implemented in Brazil as part of the fight against impunity and for the extension of access to justice. In this article, we present a rereading of the ethnographic research conducted at the Women's Police Department of João Pessoa (in the State of Paraiba, Brazil), based on the study of Canadian policies and experiences in Quebec, particularly at the Montreal Urban Community Police Department (SPCUM). In sum, this text is an essay on the "particularity" of a Brazilian experience and aims to contribute to the discussion of that type of "judiciarization" process.

Key-words: conjugal violence, women's police department, justice, police, judiciarizaton.

\section{Referências bibliográficas}

BARIL, M.; COUSINEAU, M.-M.; GRAVEL, S. Les femmes battues et la justice: l'intérvention policière. Cahiers de l'École de Criminologie, n.13, p. 1-135, 1983.

BLONDET, Cecilia; MONTERO, Carmen. La situación de la mujer en el Peru: 1980-1994. Lima, Instituto de Estudios Peruanos, 1995. (Documiento de Trabajo no. 80).

BRODEUR, J.-P. Le contrôle social: privatisation et technocratie. Déviance et Société, v. 18, n. 2, 1995.

COMMAILLE, J. Violences intra-familiales: l'exigence d'une politique publique. Cahiers de la Sécurité Intérieur. Violence en famille, $\mathrm{n}$. 28, p. 9-15, 1997.

DEBERT, G. G. Políticas públicas e o direito à diferença: as delegacias especiais de polícia. Texto apresentado na XXV Reunião Anual da ANPOCS, Caxambu, 2001.

GAUTHIER, S. La remise en liberté sous conditions par les policiers des hommes accusés dans une affaire de violence conjugale: résultats préliminaires. Montreal, 2000. (Conferência de Pesquisa no Centro Internacional de Criminologia Comparada da Universidade de Montreal). 
GREGORI, M. F. Cenas e queixas: um estudo sobre mulheres, relações violentas e prática feminista. Rio de Janeiro: Paz e Terra, São Paulo: ANPOCS, 1993.

GROSSI, M. Novas/velhas violências contra a mulher no Brasil. Revista Estudos Feministas, n. 4, 1995.

JUVÊNCIO, F. C.; BAPTISTA, V. A. As Delegacias de Polícia de Proteção ao Idoso em São Paulo e Campinas. Texto apresentado na XX Reunião Brasileira de Antropologia, Salvador, 1996. Mimeogr.

MUNIZ, J. Os direitos dos outros e outros direitos: um estudo sobre a negociação de conflitos nas DEAMS/RJ. In: SOARES, Luiz Eduadro et ali. Violência e política no Rio de Janeiro. Rio de Janeiro: ISER, Relume Dulmará, 1996. p. 125-163.

PLAISANT, É. La police dans les différends familiaux. Les Cahiers de la Sécurité Intérieur, n. 28, 1997.

RIFIOTIS, T. A mídia, o leitor-modelo e a denúncia da violência policial: o caso Favela Naval (Diadema). Revista São Paulo em Perspectiva, v. 13, n. 4, 1999a.

. Nos campos da violência: diferença e positividade. Antropologia em Primeira Mão, n. 19, 1997.

. Étude de l'identité des femmes commissaires de police du Commissariat Spécial de Protection de la Femme dans l'État de Santa Catarina (Brésil). In: WORLD CONGRESS OF SOCIOLOGY, 14, 1998, Montréal.

La stratégie judiciaire et les pratiques policières dans les Commissariats Spéciaux de Protection de Femmes au Brésil. In: SYMPOSIUM INTERNATIONAL DE VICTIMOLOGIE, 10., 2000, Montreal.

. How to recognize good policing: notes about the evaluation of police services. Policing in Democratic Societies, Newsletter of Human Rights Research and Education Center. University of Ottawa. v. 1, n. 5, 2000b. Disponível em: <www.uottawa.ca/hrrex/brazil/pds/no.5>

. Horizons to think about police services: comments about the interview with Dominique Monjardet. Policing in Democratic Societies, Newsletter of Human Rights Research and Education Center. University of Ottawa. v. 1, n. 5, 2000c. Disponível em: <www.uottawa.ca/hrrex/brazil/pds/no.5> 
RIFIOTIS, T. Les médias et les violences : points de repères sur la 'réception'. Primeira Mão, n. 45, p. 1-16, 2001.

RIFIOTIS, T.; MONJARDET, D. Les services de police en quatre actes: l'évaluation, les demandes sociales, la culture policière et le monopole de la force légitime. Une interview avec Dominique Monjardet. Policing in Democratic Societies, Newsletter of Human Rights Research and Education Center. University of Ottawa, v. 1, n. 5, $2000 \mathrm{~d}$. Disponível em:<<www.uottawa.ca/hrrex/brazil/pds/no.5〉>

RINFRET-RAYNOR, M.; CANTIN, S. (Dir.). Violence conjugale: recherches sur la violence faite aux femmes en milieu conjugal. Montréal: Gaëtan Morin, 1999.

SHERMAN, L. Policing domestic violence: experiments and dilemmas. New York: The Free Press, 1992.

SOARES, B. M. Mulheres invisíveis: violência conjugal e novas políticas de segurança. Rio de Janeiro: Civilização Brasileira, 2000.

WEBER, M. Économie et société 1. Paris: Plons, 1995a. Économie et société 2. Paris: Plons, 1995 b. 